\title{
MOTIVAÇÃo PARA PERMANÊNCIA E ÊXITO DOS LICENCIANDOS EM QUímiCA NO INSTITUTO FEDERAL DE Educação, Ciência e Tecnologia de São Paulo
}

\author{
MOTIVATION FOR PERMANENCE AND SUCCESS OF PRESERVICE \\ CHEMISTRY TEACHERS AT FEDERAL INSTITUTE OF EDUCATION, SCIENCE \\ AND TECHNOLOGY OF SÃO PAULO
}

DOI: 10.23926/RPD.2526-2149.2020.v5.n2.p999-1018.id669

\section{Ricardo Castro de Oliveira \\ Doutor em Ciências \\ (UFSCar) \\ Professor do Instituto \\ Federal de São Paulo \\ (IFSP/Câmpus Catanduva) \\ ricardocastroifsp@gmail.co \\ $\underline{\mathrm{m}}$}

\section{Jackson Gois}

Doutor em Educação (USP)

Professor do Departamento

de Educação da

Universidade Estadual

Paulista (UNESP/Câmpus de

São José do Rio Preto)

jackson.gois@unesp.br
Resumo: Levantamentos apontam para uma carência de professores de Química na Educação Básica. A baixa procura pelos cursos de Licenciatura em Química aliada a elevadas taxas de evasão contribuem para agravar esse cenário. Nesse sentido, é fundamental o desenvolvimento de estudos que abordam a permanência e êxito dos estudantes nos cursos. Este trabalho teve como objetivo conhecer o perfil dos licenciandos em Química no IFSP. O estudo contou com a participação de 524 estudantes, por meio do preenchimento de um questionário que levantou o perfil socioeconômico e as motivações para cumprirem os pré-requisitos para a conclusão do curso. Os resultados apontaram que, em geral, os licenciandos estão motivados, no entanto, alguns pré-requisitos como a PCC e o ECS precisam de maior atenção, por conta da baixa motivação envolvida no seu cumprimento. Espera-se que esses resultados possam suscitar discussões visando a melhorias nos cursos de Licenciatura em Química.

Palavras-chave: Formação de professores. Química. Teoria da Autodeterminação.

\begin{abstract}
Surveys point out to a lack of Chemistry teachers in Basic Education. Both the low search for majors in preservice Chemistry teachers and the high dropout rates contribute to aggravate this scenario. In this sense, the development of studies which approach the students' permanence and success in the courses is essential. This work aimed to collected the profile of preservice Chemistry teachers at IFSP. The study counted on the participation of 524 students, through the filling of a questionnaire which raised the socioeconomic profile and the motivations to meet the prerequisites for concluding the major. The results pointed out that, in general, preservice teachers are motivated, however, some prerequisites like PCC and ECS need more attention, due to the low motivation involved in their accomplishment. It is expected that these results may evoke discussions aiming at improvements of the majors in preservice Chemistry teachers.
\end{abstract}

Keywords: Teacher education. Chemistry. Self-determination Theory. 


\section{INTRODUÇÃ̃O}

A formação de professores tem sido o foco de inúmeros trabalhos na área de Educação em Química. Uma preocupação constante dos pesquisadores se refere à baixa procura pelos cursos de Licenciatura em Química, que se deve, em parte, à desvalorização profissional e social do professor (RUIZ; RAMOS; HINGEL, 2007; DAMASCENO et al. 2011; SÁ; SANTOS, 2016), condições inadequadas de ensino, violência nas escolas, falta de um plano de carreira atraente, entre outros (RUIZ; RAMOS; HINGEL, 2007). Esses fatores também contribuem para a elevada taxa de evasão nos cursos de Licenciatura (MAZETTO; BRAVO; CARNEIRO, 2002; SÁ; SANTOS, 2006) e para a inserção dos licenciados no mercado de trabalho em áreas diferentes do magistério (DAMASCENO et al. 2011).

Ruiz, Ramos e Hingel (2007) apontaram para um possível “apagão" do Ensino Médio no Brasil. Para esses autores, a quantidade de vagas oferecidas nos cursos de Licenciatura é insuficiente para suprir a demanda de professores. Somado a isso, a procura pelos cursos de Licenciatura tem sido cada vez menor, decorrente, principalmente, da desvalorização da carreira docente. Ressalta-se ainda a elevada taxa de evasão nesses cursos, o que agrava ainda mais a situação. A falta de professores para atuar na Educação Básica abrange todas as áreas, em especial, nas disciplinas de biologia, física, matemática e química.

A situação apontada por Ruiz, Ramos e Hingel (2007) não mudou no cenário atual. A carreira docente continua sendo pouco atrativa para os estudantes. De acordo com o Censo da Educação Superior de 2018 (BRASIL, 2019), apenas 20,5\% dos ingressantes optaram por cursos de Licenciatura. Levando em consideração o número total de estudantes matriculados nessa modalidade, o percentual é muito parecido e corresponde a 19,4\% das matrículas. Esse número é muito baixo, se comparado aos cursos de bacharelado, que predominaram com quase $68 \%$ dos estudantes matriculados no Ensino Superior.

Em 2018, pela primeira vez, o número de matriculados em cursos de Licenciatura a distância $(50,2 \%)$ superou o número de matrículas nos cursos presenciais $(49,8 \%)$, o que evidencia o elevado crescimento dessa modalidade de ensino nos últimos anos. A maioria dos licenciandos $(71,3 \%)$ pertence ao sexo feminino e uma parcela de $28,7 \%$ ao sexo masculino. $\mathrm{O}$ curso de Pedagogia correspondeu à maioria das matrículas com $45,9 \%$, seguido pelo curso de Educação Física com 10,3\%. O curso de Licenciatura em Química ocupou a nona posição com 37.881 matrículas $(2,3 \%)$.

Essa baixa procura, aliada a elevadas taxas de evasão nos cursos, refletem diretamente na falta de docentes de Química no mercado de trabalho. Para não prejudicar os estudantes, 
muitas vezes essas vagas são ocupadas por profissionais despreparados para atuar em sala de aula. Segundo o censo da Educação Superior (BRASIL, 2019), 38,1\% dos docentes da disciplina de química, que atuam no Ensino Básico, não apresentam a habilitação adequada, o que é muito preocupante, uma vez que pode impactar diretamente a qualidade do ensino. Para diminuir essa carência de docentes na área, Sá e Santos (2016, p.111) afirmam que é necessário um conjunto de ações públicas que visem modificar a representação social dos professores que foi construída ao longo do tempo. Para esses autores:

\begin{abstract}
A alteração dessa representação demanda que os salários dos docentes sejam equiparados com o salário de outras carreiras de nível superior; demanda um plano de carreira específico e o estímulo à formação continuada; demanda a criação de condições de trabalho dignas, o que inclui a dedicação exclusiva a uma única escola, com horário determinado dentro da carga horária para planejamento, elaboração de atividades, bem como correções de trabalhos e avaliações de aprendizagem; demanda menor carga horária em sala de aula e salas com menos estudantes; demanda ambiente escolar seguro, organizado e confortável, enfim, um local em que professores, funcionários e estudantes sintam prazer de estar e possam desenvolver suas potencialidades (SÁ; SANTOS, 2016, p.111).
\end{abstract}

A permanência dos licenciandos nos cursos é um ponto que merece destaque e colabora para diminuir a carência de docentes na área. Nesse sentido, a formação de professores de Química tem sido investigada em trabalhos na literatura a partir de diversos temas. Dentre os temas da formação de professores de Química, a motivação de professores e estudantes tem recebido pouco destaque, apesar de estar presente em importantes trabalhos (MILARÉ; WEINERT, 2016; SÁ; SANTOS, 2016; BEGO; FERRARI, 2018; FERRARI; CORTELA, 2018; JULIÃO; DA COSTA; BEZERRA, 2018; RIBEIRO, 2019; TOLEDO; COUTINHO, 2020).

Os cursos de Licenciatura são regidos pela Resolução CNE/CP 02/2015 (BRASIL, 2015), que define as Diretrizes Curriculares Nacionais para os cursos de formação inicial e continuada de professores. Essa resolução estabelece uma carga horária mínima de 3.200 horas para os cursos, sendo 2.200 horas em disciplinas (técnicas e pedagógicas), 200 horas de atividades teórico-práticas (ATP), 400 horas de Estágio Curricular Supervisionado (ECS) e 400 horas de Prática como Componente Curricular (PCC).

\title{
2 REFERENCIAL TEÓRICO
}

Para que os estudantes possam permanecer no curso e concluí-lo, é essencial que estejam motivados para cumprir os pré-requisitos estabelecidos na Resolução CNE/CP 02/2015 (BRASIL, 2015). A Psicologia e, mais especificamente, a Teoria da Autodeterminação (DECI; 
RYAN, 1985) podem ser aliadas importantes na compreensão de aspectos centrais da motivação dos licenciandos.

Anteriormente à apresentação da Teoria da Autodeterminação, os estudos apontavam para a existência de dois tipos de motivação: a extrínseca e a intrínseca. Ryan e Deci (2000a) expandem a compreensão sobre motivação ao propor um continuum de motivação, representado na figura 1.

Figura 1 - Continuum de autodeterminação com os diferentes tipos de motivação

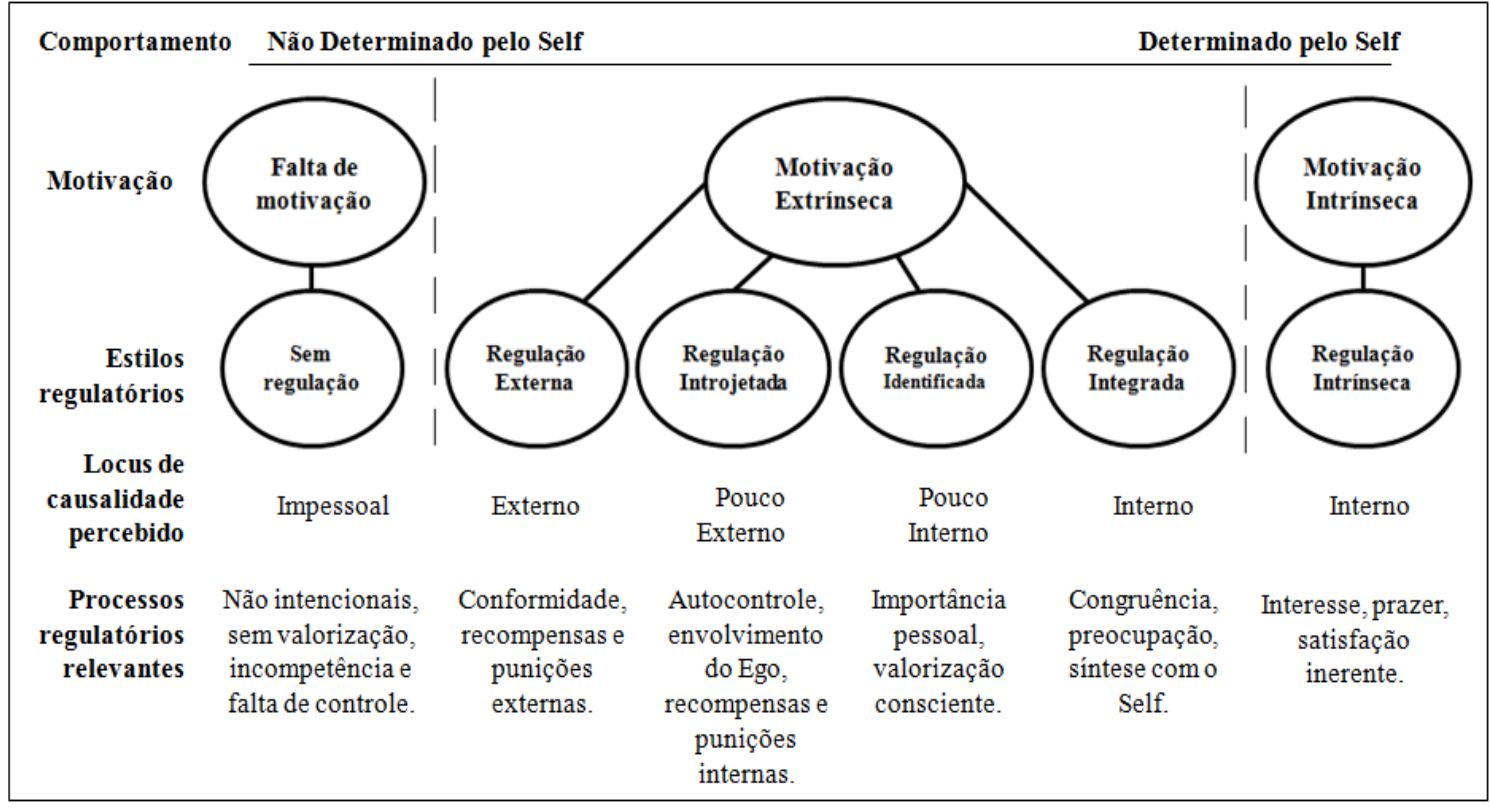

Fonte: Ryan e Deci (2000a).

Para Ryan e Deci (2000a) o continuum é composto pelas categorias desmotivação (falta de motivação), motivação extrínseca (subdividida de acordo com os estilos regulatórios em externa, introjetada, identificada e integrada) e motivação intrínseca.

$\mathrm{Na}$ falta de motivação o indivíduo não apresenta intenção de agir, mesmo na presença de fatores externos como prêmios ou punições. Na motivação extrínseca por regulação externa e introjetada, os comportamentos são fortemente influenciados por fatores externos. No entanto, na introjetada os comportamentos são direcionados para evitar culpa, ansiedade e satisfação do ego. Esses tipos de motivação extrínseca apresentam baixo grau de autodeterminação e estão relacionados a resultados insatisfatórios de desempenho, sendo, portanto, indesejáveis no ambiente escolar (RYAN; DECI, 2000b).

Ao percorrer o continuum, encontram-se as formas mais autodeterminadas de motivação extrínseca: a identificada e a integrada. Nesses tipos, os indivíduos agem conscientemente por identificar a importância da tarefa, porém, na integrada, os regulamentos são inteiramente assimilados ao Self, indo ao encontro dos valores e necessidades dos indivíduos. A forma mais 
autodeterminada de motivação refere-se à intrínseca, na qual os indivíduos realizam as tarefas pelo interesse e satisfação resultantes, independente da presença de fatores externos (RYAN; DECI, 2000a).

Quanto mais próxima da motivação intrínseca, mais autônoma e autodeterminada será a motivação. Essas formas são as desejáveis no ambiente escolar, visto estarem relacionadas a desempenhos satisfatórios, desenvolvimento social e bem-estar psicológico (RYAN; DECI 2000a; REEVE, 2006).

É importante ressaltar que o estado motivacional de um indivíduo para a realização de tarefas não é imutável, ou seja, pode variar de acordo com o meio. Segundo Ryan e Deci (2000b), a motivação está diretamente atrelada às necessidades psicológicas básicas de competência, autonomia e pertencimento. No atendimento dessas necessidades, o indivíduo apresenta motivação para realizar a tarefa; em contraposição, na ausência dessas necessidades, o estudante apresenta baixa motivação e, consequentemente, baixo engajamento na tarefa.

Para Ryan e Deci (2000b), a necessidade de competência está relacionada ao desempenho eficaz na execução de uma tarefa. Para isso, é fundamental que as atividades sejam claras e de acordo com as habilidades do indivíduo. Para Reeve (2006, p.73),

\footnotetext{
Quando participamos de uma tarefa cujo grau de dificuldade e complexidade encontra-se precisamente no nível de nossas habilidades atuais, experimentamos então o mais forte interesse e o maior envolvimento possível com a nossa necessidade de competência (REEVE, 2006, p.73).
}

É compensador, quando conseguimos realizar uma tarefa com sucesso. No entanto, nem sempre isso ocorre no ambiente escolar. Visando contribuir para satisfazer essa necessidade, Reeve (2006) elenca algumas atitudes que podem ser tomadas, tais como expor de forma clara as expectativas e os procedimentos, apresentar desafios em nível ótimo, apresentar sugestões para o progresso do indivíduo e fornecer feedbacks adequados.

Outra necessidade psicológica básica se refere à autonomia. De acordo com Reeve (2006), todo indivíduo deseja tomar decisões, decidir como, onde e como realizar determinadas tarefas, em lugar de seguir ordens dos outros. Essa necessidade precisa estar presente no ambiente escolar, uma vez que é essencial para a motivação do estudante. Para Reeve (2006), algumas ações podem contribuir para satisfazer essa necessidade, entre as quais se destacam ouvir com atenção, permitir que os outros se expressem, incentivar o esforço, fornecer justificativas racionais, elogiar o progresso, questionar o que os outros querem fazer, reconhecer a perspectiva do outro e afins. 
É importante ressaltar que as necessidades psicológicas básicas de competência e autonomia devem ser trabalhadas paralelamente. Para Deci e Flaste (1995, p.76) "a busca por competência e autonomia juntas, impulsionada pela curiosidade e interesse, é, portanto, força de crescimento que leva as pessoas a se tornarem cada vez mais realizadas e a continuarem aprendendo por toda a vida".

O pertencimento refere-se à outra necessidade psicológica. Para Reeve (2006), todo indivíduo busca o relacionamento com outras pessoas e grupos e deseja ser aceito e valorizado pelas pessoas próximas. Para que um indivíduo se envolva nas atividades propostas é fundamental que se sinta parte do meio em que se encontra. Para isso, Reeve (2006) elenca algumas ações que podem ser postas em prática para suprir essa necessidade, tais como se preocupar com os outros, demonstrar afeto e apreço pelas pessoas, conhecer o outro, compartilhar recursos pessoais, como tempo, atenção e apoio emocional e outras mais.

O conhecimento sobre motivação, em especial, a Teoria da Autodeterminação (DECI; RYAN, 1985) pode dar subsídios essenciais para o planejamento de ações que visam motivar os estudantes a permanecerem na Instituição. Nesse sentido, pode-se tornar uma aliada importante nos cursos de Licenciatura, em especial, àqueles que apresentam elevada taxa de evasão, como é o caso da Química.

Discutir a formação de professores no momento atual é de extrema importância. Apesar da constante desvalorização da carreira docente, é preciso buscar, constantemente, meios para estimular a procura pelos cursos de Licenciatura, assim como propor ações visando à permanência e ao êxito dos que estão matriculados nesses cursos. Nesse sentido, é muito importante o desenvolvimento de estudos como esse, que intenta traçar o perfil dos estudantes, pois é o ponto de partida para a tomada de inúmeras decisões pretendendo melhorias para os cursos de formação de professores.

O presente trabalho teve como objetivo levantar o perfil dos licenciandos em Química no Instituto Federal de Educação, Ciência e Tecnologia de São Paulo (IFSP). Trata-se de um dos principais centros de formação de professores de Química no Estado de São Paulo. O IFSP é constituído por 36 câmpus, estando o curso de Licenciatura em Química presente em oito municípios: Barretos, Capivari, Catanduva, Matão, São José dos Campos, São Paulo, Sertãozinho e Suzano. Além desses, o Câmpus São João da Boa Vista oferece o curso de Licenciatura em Ciências Naturais com habilitação em Física e Química. Nesse caso, esse câmpus também foi contemplado no presente estudo. 
Além de contribuir para o desenvolvimento da área, o presente estudo buscou o aporte da Psicologia para discutir a formação de professores no IFSP. Esse envolvimento de diferentes áreas é enriquecedor e nos auxilia diretamente na compreensão dos problemas e desafios a serem superados.

\section{Metodologia}

Este estudo, envolvendo abordagem quali-quantitativa, foi aprovado pelo Comitê de Ética do IFSP (CAAE: 14213819.9.3001.5473, em 27/06/2019). Todos os licenciandos em Química da Instituição foram convidados para participar da pesquisa. A coleta de dados foi realizada, presencialmente, em cada câmpus, por um dos autores deste estudo, por meio da aplicação de um questionário impresso e teve a duração de aproximadamente 30 minutos.

O questionário é definido por Gil (1999, p.128) como “a técnica de investigação composta por um número mais ou menos elevado de questões apresentadas por escrito às pessoas, tendo por objetivo o conhecimento de opiniões, crenças, sentimentos, interesses, expectativas, situações vivenciadas etc”. Nesse sentido, o questionário é amplamente utilizado como instrumento de coleta de dados na área de Educação.

O questionário utilizado neste estudo foi elaborado pelos autores do trabalho e apresentou questões fechadas e abertas. As questões fechadas tinham por objetivo traçar o perfil socioeconômico dos participantes, assim como os motivos pela escolha do curso e a motivação para cumprir os pré-requisitos necessários à obtenção do diploma de licenciado em Química. Para esses itens, o licenciando deveria assinalar a motivação para o seu cumprimento, em uma escala do tipo Likert, que variava de 1 a 7 , onde 1 correspondia a "totalmente desmotivado", 4 a "nem desmotivado e nem motivado" e 7 a "totalmente motivado". Quanto mais próximo de 7, maior a motivação para cumprir o requisito. Os resultados referem-se às médias obtidas, a partir das respostas de cada item. A média para analisar a motivação foi utilizada em diferentes trabalhos (ARAÚJO, 2015; GUIMARÃES; BZUNECK, 2008; CANUTO, 2018).

Nas questões abertas, os participantes poderiam descrever os aspectos que motivavam e desmotivavam os licenciandos no curso. Para Lüdke e André (2013), além de contribuir para a análise, a proposição dessas questões permite a articulação dos dados com os pressupostos teóricos utilizados no trabalho. Nesse sentido, as questões abertas forneceram subsídios para dialogar com as questões fechadas, bem como para promover a articulação dos dados com os referenciais. O conjunto das questões forneceram dados importantes para traçar o perfil dos licenciandos em Química no IFSP. 


\section{Resultados}

Embora os licenciandos em Química no IFSP estejam localizados em diferentes câmpus distribuídos pelo Estado de São Paulo, com diferenças culturais e de mercado de trabalho, não foi possível constatar diferenças significativas entre eles, assim como entre os estudantes de um mesmo período do curso em diferentes câmpus. Nesse caso, observou-se homogeneidade nos resultados e, diante disso, optou-se, neste trabalho, por organizar os resultados em um único conjunto e, assim, traçar um panorama geral dos participantes.

Este estudo contou com a participação de 524 licenciandos em Química no IFSP, sendo $324(61,8 \%)$ do sexo feminino e $200(38,2 \%)$ do sexo masculino, com a média de idade de 23,5 anos. Em relação à cor, $65,5 \%$ se autodeclararam brancos, $24,2 \%$ pardos, indígenas ou amarelos e apenas 10,3\% negros. Em sua maioria, 70,8\% cursaram todo o Ensino Médio na rede pública, 25,6\% na rede privada e 3,4\% na rede pública e privada. Para Gatti et al. (2019), o número expressivo de estudantes da rede pública nas Licenciaturas evidencia a "popularização" desses cursos, uma vez que esses estudantes representam a maioria da população. Em relação à escolarização dos pais, os dados estão organizados na Figura 2:

Figura 2 - Escolarização dos pais dos participantes da pesquisa

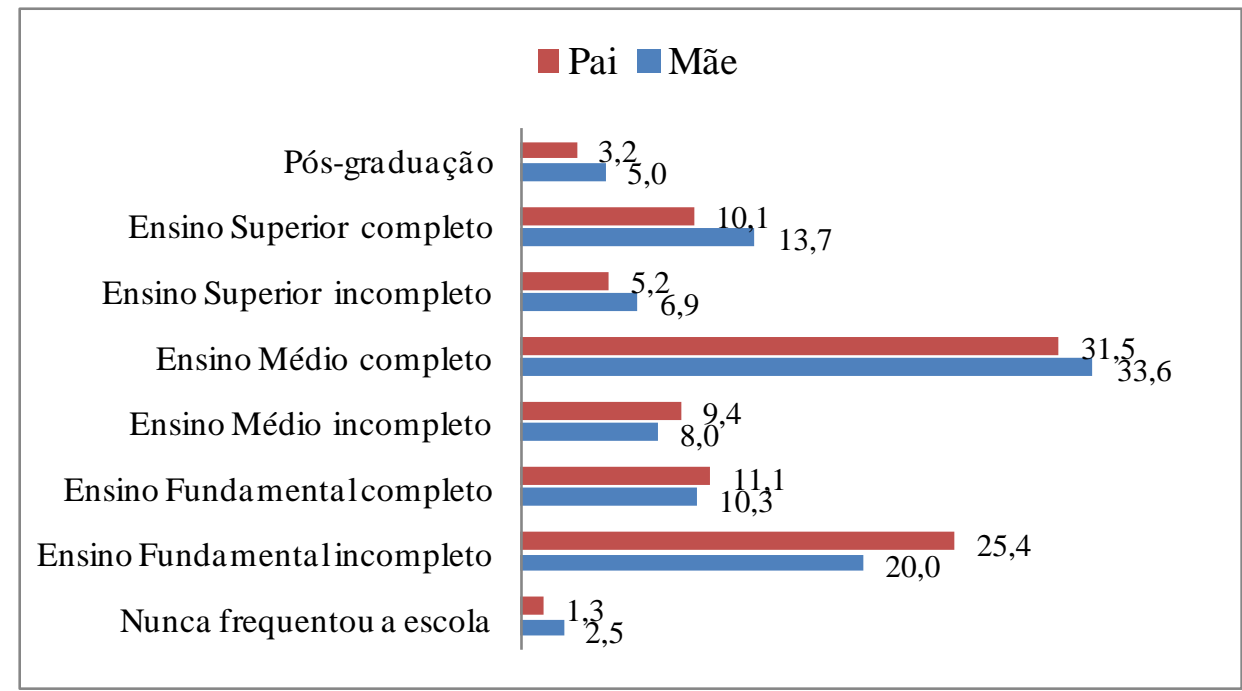

Fonte: Autoria própria

Nota-se que, em geral, as famílias dos participantes apresentaram baixo grau de escolarização, com o predomínio do Ensino Médio completo e maior escolarização da mãe em relação ao pai. De acordo com Gatti et al. (2019), as famílias dos estudantes de Licenciatura apresentam baixo nível de escolarização, se comparados a profissões mais privilegiadas, como medicina, por exemplo. Para esses autores, a maioria dos docentes da Educação Básica tornouse a primeira geração na família com formação de nível superior. 
Ainda em relação às famílias, a maioria $(61,6 \%)$ apresentou renda de até três salários mínimos. Nesse caso, os auxílios estudantis são fundamentais para que os estudantes tenham condições de permanecer na Instituição. Infelizmente, são muito comuns relatos de estudantes que tiveram que abandonar o curso por conta de problemas financeiros. Uma parcela de 43,9\% dos licenciandos recebe algum tipo de auxílio, como moradia, alimentação, transporte ou outra bolsa fornecida pela Instituição (monitoria, iniciação científica, projetos de extensão entre outras).

Uma parcela de 38,5\% dos licenciandos em Química do IFSP trabalha. Em relação a esse tópico é importante ressaltar que há uma diferença significativa entre os estudantes dos diferentes turnos. A maioria $(60,1 \%)$ está matriculada no período matutino, sendo que $27,3 \%$ deles trabalham. Uma parcela de 39,9\% está matriculada no período noturno e desses, 55,5\% trabalham. Desse modo, constata-se que a maioria dos estudantes que trabalha está matriculada no período noturno.

Em relação ao percurso formativo dos licenciandos em Química no IFSP em 2019, $33,6 \%$ dos participantes da pesquisa eram ingressantes, $24,8 \%$ estavam cursando o segundo ano, $20,4 \%$ o terceiro ano e $21,2 \%$ estavam no último ano ou cursando alguma pendência. É importante destacar que a quantidade de estudantes foi diminuindo com o passar dos anos e isso está relacionado à evasão, que foi aumentando gradativamente no decorrer do processo formativo.

A Licenciatura em Química não foi a primeira opção para 58,6\% dos participantes. No entanto, eles foram se identificando com a profissão ao longo do curso e, ao serem questionados sobre a atuação futura, 70,0\% apontaram o desejo de atuar na docência:

O curso era uma segunda opção, hoje é amor a licenciatura em química, e se fosse para escolher não escolheria outro curso (Estudante $188,4^{\circ}$ ano do curso).

Ao passar dos semestres vou me interessando mais pelas matérias pedagógicas, nas quais não me imaginava cursando, e ao passar dos semestres o interesse aumenta como um todo. Antes de iniciar o curso não me imaginava lecionando, hoje já vejo essa possibilidade (Estudante 337, $1^{\circ}$ ano do curso).

Inicialmente pretendia cursar bacharelado em química, mas durante o início do curso me identifiquei com os conteúdos e discussões que ocorriam e decidi continuar com o curso... Hoje não penso em seguir outra carreira, me sinto motivado a seguir na docência (Estudante 363, $3^{\circ}$ ano do curso).

Diante do cenário em que a maioria não elegeu a Licenciatura em Química como primeira opção, fica o questionamento sobre o que teria levado esses estudantes a escolherem o curso. Os resultados indicaram que "afinidade e facilidade com a disciplina" foi apontado por $51,7 \%$ dos participantes como principal motivo pela escolha, seguido pela "inspiração em 
professores do ensino fundamental e/ou médio" com 38,7\%, "pelas múltiplas opções do mercado de trabalho" com 32,6\%, "por não ter o curso que pretendia na região e a Licenciatura em Química era o que mais se aproximava" com 26,7\%, "porque sente que possui o dom para lecionar" com 22,5\%,"por ser uma profissão socialmente importante" com 19,1\% entre outros motivos. A função social atribuída ao professor apareceu com frequência nos relatos dos licenciandos:

Os fatores que mais me motivam no curso de licenciatura em química é levar o conhecimento de diversas maneiras a pessoas que não tem (sic). Principalmente no ensino público, onde esta disciplina é completamente desfalcada (Estudante 137, $1^{\circ}$ ano do curso).

O fator primordial é o sonho de uma educação pública de qualidade para as próximas gerações. O IF me faz muitas provocações para que eu melhore na vida profissional e pessoal (Estudante 172, $2^{\circ}$ ano do curso).

A perspectiva com o âmbito social no qual é evidente a influência na sociedade. Estudo para ser a diferença onde acredito que o professor nos dias atuais é a mais importante ferramenta revolucionária (Estudante $311,4^{\circ}$ ano do curso).

Chama a atenção que o motivo "prestígio e status da carreira docente" tenha sido assinalado por $6,1 \%$ e a "remuneração da profissão" por $4,4 \%$ dos participantes. Ao serem questionados sobre os fatores que mais desmotivam em relação à carreira, apontaram a:

A desvalorização dos professores, o baixo salário, as péssimas condições no ambiente de trabalho (salas superlotadas, materiais didáticos ruins, desmotivação dos alunos) (Estudante 190, $4^{\circ}$ ano do curso).

Um fator desmotivador é a realidade política a qual sabemos que seremos inseridos, a qual desvaloriza e desmotiva a todo momento a profissão do professor (Estudante $322,1^{\circ}$ ano do curso).

Desvalorização do docente da rede pública do Estado e a estrutura das escolas públicas na rede pública do Estado (Estudante 370, $4^{\circ}$ ano do curso).

Os fatores levantados pelos estudantes vão ao encontro dos apontados na literatura (RUIZ; RAMOS; HINGEL, 2007; DAMASCENO et al. 2011; SÁ; SANTOS, 2016). Ainda em relação à futura atuação profissional, 40,8\% assinalaram o desejo de atuar na indústria:

O que me motiva é eu querer me formar, ter um diploma e poder atuar na indústria”, (Estudante $187,1^{\circ}$ ano do curso).

$\mathrm{O}$ anseio de atuar em centros de pesquisa foi apontado por 39,5\% dos participantes:

Os fatores que mais me motivam no curso de licenciatura em química é (sic) poder desenvolver e trabalhar com pesquisa futuramente (Estudante 142, $1^{\circ}$ ano do curso).

Apenas 12,8\% assinalaram que pretendem atuar fora da área de formação. É importante ressaltar que os estudantes poderiam assinalar mais de uma opção nesse item.

Em relação aos hábitos de estudo, a maioria (35,7\%) apontou que estuda até duas horas por dia, 32,4\% que não estudam diariamente, $26,3 \%$ estudam de duas até quatro horas e apenas 
5,5\% que estudam acima de 4 horas por dia. Em relação aos estudos após a conclusão, 76\% apontaram que pretendem continuar os estudos, cursando uma especialização, um mestrado ou doutorado, 26,5\% que gostariam de cursar o Bacharelado em Química, 31,3\% cursar outra graduação e apenas 3,6\% não gostariam mais de estudar. Os resultados evidenciaram que os estudantes reconhecem a importância de buscar uma formação continuada, visando aprimorar a sua formação e, consequentemente, melhorar o seu desempenho no trabalho.

É importante mencionar que a motivação do estudante está relacionada ao atendimento das necessidades psicológicas básicas de competência, autonomia e pertencimento (RYAN; DECI, 2000a; REEVE, 2006). No que se refere à competência, os participantes fizeram uma autoavaliação sobre o seu desempenho (rendimento acadêmico) nas disciplinas do curso, em uma escala do tipo Likert que variava de 1 a 7, onde 1 correspondia a "muito insatisfatório" e 7 a "muito satisfatório". A média encontrada para os participantes foi de 4,8. É um valor expressivo, porém, ainda distante da nota máxima. Alguns relatos evidenciaram dificuldades em algumas áreas específicas que compõem o currículo, tais como Física e Matemática.

Os cálculos avançados, tenho bastante dificuldade em física e cálculo. Acho que sinto um desfalque grande dessas duas matérias até agora, mas de restante eu amo muito estar aqui (Estudante 29, $2^{\circ}$ ano do curso).

As matérias de cálculo, matemática e a grande quantidade de coisas para se fazer em casa, impossibilitando de darmos $100 \%$ para algo. Me sinto atropelada (Estudante $305,1^{\circ}$ ano do curso).

De modo geral, os estudantes apresentaram maior média de motivação para cursar as disciplinas técnicas $(5,7)$, em detrimento das disciplinas pedagógicas $(5,0)$, em uma escala que variava de 1 a 7 . Esses resultados apontaram que, em geral, os estudantes estão motivados para cursar as disciplinas do curso. No entanto, esse índice pode melhorar quando os estudantes tiverem a necessidade de competência e autonomia nutridas. Para isso, Reeve (2006) sugere algumas ações, tais como oferecer desafios aos estudantes, bem como feedbacks adequados. Uma disciplina que envolve apenas memorização e reprodução de conhecimentos, na maioria das vezes, não promove a motivação e, consequentemente, o envolvimento e a aprendizagem do estudante. Nesse caso, fica no estudante a sensação de que ele passou por uma disciplina e não aprendeu nela o que desejava.

Embora não seja frequente, é possível encontrar certa resistência em relação às disciplinas pedagógicas e, muitas vezes, são deixadas em segundo plano, se comparadas às disciplinas técnicas. Os depoimentos a seguir evidenciaram essa resistência: 
O curso oferece uma grade com um número muito grande de disciplinas pedagógicas que são na minha opinião sempre a mesma coisa enquanto deixa de ofertar disciplinas de química que seriam importantes para a formação (Estudante 204, $4^{\circ}$ ano do curso).

\begin{abstract}
Algumas matérias pedagógicas que acabam falando da mesma coisa, e portanto, poderiam tornar-se uma só, como por exemplo história da educação e psicologia da educação e dar espaço para matéria mais específica da química, como química quântica e química computacional. Além disso, algumas matérias são tratadas de forma superficial. Tem também o fato de, sim, é importante matéria pedagógica, mas não adianta nada o aluno saber vários métodos e não dominar a química em si, tornando-se uma pessoa rasa em química (Estudante 210, $4^{\circ}$ ano do curso).
\end{abstract}

De acordo com os relatos, ainda é possível encontrar nos estudantes a visão de que as disciplinas técnicas são mais importantes que as disciplinas pedagógicas e que para ser um bom professor basta dominar o conteúdo químico. Para Schnetzler e Aragão (1995), é comum encontrar essa visão simplista de atividade docente, a de que basta ter o domínio de conteúdos específicos e de algumas técnicas de ensino para estar apto a lecionar. Essa visão precisa ser amplamente debatida e desconstruída nos cursos de formação de professores.

Como pré-requisito para a conclusão do curso de Licenciatura, a Resolução CNE/CP 02/2015 (BRASIL, 2015) estabelece que os estudantes precisam cumprir 400 horas de PCC. Em todos os cursos de Licenciatura em Química do IFSP, a carga horária da PCC é distribuída em disciplinas, tanto específicas quanto pedagógicas, ao longo de todo processo formativo. Essa prática deve estar voltada ao ensino, sempre buscando o diálogo entre a teoria e a prática, podendo ser desenvolvida por meio de sequências didáticas, análise e produção de materiais didáticos, adaptações e utilização de materiais didáticos, estudos de casos, jogos, simulações, seminário entre outras mais.

Em relação ao desenvolvimento das atividades envolvendo a PCC, os estudantes apresentaram média de motivação de 4,2, ou seja, baixo grau de motivação. Há relatos de estudantes apontando para a sua importância quando envolve a utilização de diferentes recursos, tais como uso de jogos, teatro, documentários, sequência didática, entre outros. No entanto, esse item foi alvo de inúmeras críticas, tais como "As altas cargas horárias referentes às práticas como componente curricular (PCC)", estudante 354, $3^{\circ}$ ano do curso; "As horas destinadas ao PCC em cada matéria me desgastam um pouco como aluna", estudante $306,1^{\circ}$ ano do curso; “PCC bagunçados ou pouco aproveitáveis", estudante 291, $1^{\circ}$ ano do curso.

É importante enfatizar que grande parte das reclamações envolvendo a PCC está relacionada à carga horária. Esse ponto não é passível de alteração, por estar previsto na Resolução CNE/CP 02/2015 (BRASIL, 2015). No entanto, é possível pensar em meios para envolver mais os estudantes nessas atividades. É importante ouvir os estudantes e, a partir das demandas levantadas, planejar as atividades. Quando o licenciando compreende a importância 
desse momento para a sua formação, age de forma consciente, apresentando motivação autodeterminada que, segundo Ryan e Deci (2000a), é a mais desejada, uma vez que está relacionada a melhores desempenhos.

Em relação ao ECS, outro pré-requisito estabelecido pela Resolução CNE/CP 02/2015 (BRASIL, 2015), a média de motivação para o seu cumprimento foi de 4,2, ou seja, também apresentou baixo grau de motivação. Cabe apontar que a carga horária do Estágio é de 400 horas, sendo realizado a partir da segunda metade do curso e, diante disso, $58,4 \%$ dos participantes não haviam iniciado essa etapa, pois estavam nos anos iniciais do curso. Para esses estudantes, a motivação para cumprir o estágio foi maior, com valores de 5,1 para os ingressantes e 4,5 para os estudantes do $2^{\circ}$ ano, o que evidencia a expectativa desses estudantes por esse momento.

No entanto, a motivação para cumprir o estágio diminuiu de forma significativa no terceiro ano $(3,7)$ e, mais ainda, nos estudantes concluintes $(3,4)$. Nesses casos, evidencia-se a falta de motivação para a realização do estágio. Nos depoimentos dos estudantes, foram recorrentes as críticas em relação ao estágio, conforme descritos a seguir:

\begin{abstract}
Por vezes são muitas coisas para fazer. O estágio obrigatório é um tanto injusto, porque não há remuneração (na verdade você paga para fazer estágio, se deslocando de lá por recursos próprios) como em outros estágios obrigatórios (engenharias, nenhum estágio, ou quase nenhum, não oferece remuneração ou auxílio transporte pelo menos) (Estudante 317, $4^{\circ}$ ano do curso).

Nas disciplinas voltadas para educação aprendemos conteúdos muito interessantes, porém durante o estágio acabamos perdendo um pouco o interesse pela educação, uma vez que é difícil associar o conteúdo visto em aula com a realidade da escola pública (Estudante 508, $4^{\circ}$ ano do curso).
\end{abstract}

Foi recorrente nos depoimentos o número excessivo de horas do estágio, excesso de burocracia, a falta de interesse dos estudantes do ensino básico, desrespeito dos estudantes com os docentes das escolas, falta de estrutura das escolas públicas, o estágio não ser remunerado e a falta de flexibilidade por parte da Instituição para organizar o estágio. Apesar das inúmeras críticas, o estágio é um momento importante para a formação do licenciando, sendo a sua relevância apontada em alguns depoimentos:

Os fatores que mais motiva o curso de química vieram a partir do estágio, onde se pode observar a valorização do professor de química e através da extensão que contribuiu para aumentar a motivação, onde você pode mostrar estratégias para fazer inovação na forma de ensino (Estudante 267, $3^{\circ}$ ano do curso).

Hoje, na segunda metade do curso tenho o contato com o ambiente escolar, através dos estágios obrigatórios e do PIBID e posso dizer que gosto de estar no ambiente escolar lidando com os alunos e se surge algum problema não penso em desistir, mas sim em como resolvê-lo (Estudante $363,3^{\circ}$ ano do curso). 
É durante o estágio que o licenciando tem a oportunidade de promover a práxis. Em sua maioria, os primeiros semestres de estágio referem-se à observação. No entanto, o estudante passa a ter maior protagonismo no decorrer do estágio, assumindo determinadas atividades durante o período de regência. É nesse período que ele pode colocar em prática os conhecimentos adquiridos nas disciplinas.

Esse protagonismo pode despertar no licenciando o sentimento de competência por conseguir desenvolver uma proposta capaz de proporcionar aprendizagem ao estudante, autonomia no sentido de construir a sua proposta e o sentimento de pertencimento, no qual se vê como parte da equipe escolar e que está contribuindo diretamente para a formação do estudante da Educação Básica. Quando o licenciando vivencia esses sentimentos, sente-se envolvido nas atividades, pois tem as necessidades psicológicas básicas atendidas e, assim, apresenta as formas mais autodeterminadas de motivação, indo ao encontro dos pressupostos defendidos por Ryan e Deci (2000a) e Reeve (2006). Tal fato contribui de forma significativa para a permanência do estudante no curso, bem como para a motivação em atuar futuramente na profissão.

Ao discutir a motivação dos licenciandos, é importante levar em consideração também algumas atividades que permeiam os cursos. Uma delas se refere ao envolvimento dos estudantes em projetos. O IFSP conta com editais de projetos de Ensino, Pesquisa e Extensão, além de programas de incentivo à docência, como o Programa Institucional de Bolsas de Iniciação à Docência (PIBID) e o Programa de Formação de Educadores (PROFE). Esses programas de incentivo à docência estão presentes em todos os cursos de Licenciatura em Química da Instituição. Uma parcela de 24,6\% dos licenciandos recebe algum tipo de bolsa de ensino, pesquisa ou extensão. Esse envolvimento é importante para a motivação desses estudantes, conforme corroborado nos depoimentos:

Os principais fatores são as minhas pesquisas de iniciação científica, a busca pelo conhecimento, afinal é a partir deles que eu entendo o que faço (Estudante $118,3^{\circ}$ ano do curso).

Outra coisa o PIBID é o projeto que faz meu coração se aquecer, é um dos meios que me faz querer mais ser um docente que entende o que é ser discente (Estudante 172, $2^{\circ}$ ano do curso).

Oportunidades formativas extraclasse que permite (sic) o meu aprofundamento nos estudos, contato com a pesquisa, atividades e cursos de extensão, pois esses momentos exploram as possibilidades da práxis (teoria e prática), promovendo a significação dos conceitos e conhecimentos apreendidos (Estudante $44,4^{\circ}$ ano do curso).

É durante o desenvolvimento de projetos e atividades extracurriculares que os licenciandos têm a oportunidade de vivenciar novas experiências, de sentirem-se competentes, 
com autonomia para desenvolver trabalhos na área de que gostam, de tomar decisões, de sentirem-se parte da Instituição. Esses fatores vão ao encontro das necessidades psicológicas básicas, que são essenciais para a motivação de todo indivíduo, defendido por Ryan e Deci (2000a) e Reeve (2006). Nesse sentido, é fundamental que as Instituições incentivem a participação dos licenciandos em atividades extracurriculares, tais como de Ensino, Pesquisa e Extensão, pois isso contribui de forma significa para a permanência e, consequentemente, para o êxito dos estudantes no curso. Nos cursos de Licenciatura em Química, no IFSP, os projetos e as atividades extracurriculares são contabilizados como horas de ATP, que os estudantes precisam cumprir 200 horas ao longo do curso.

Outro aspecto relevante é o papel do docente na motivação. Para Guimarães e Boruchovitch (2004, p.147), “a motivação intrínseca do aluno não resulta de treino ou de instrução, mas pode ser influenciada principalmente pelas ações do professor”. Nesse sentido, torna-se evidente a importância do docente na motivação dos estudantes. Em uma escala de 1 a 7, onde 7 representa a maior motivação, os licenciandos avaliaram com média 5,8 a motivação dos docentes que atuam nos cursos de Licenciatura em Química da Instituição. A importância do professor é apontada nos depoimentos dos estudantes:

O que mais me motiva para o curso da licenciatura em química são meus professores e as atividades fornecidas no campus, já que os docentes dão muito apoio aos alunos e o instituto proporciona experiências e aprendizados únicos (Estudante $72,1^{\circ}$ ano do curso).

Os fatores que mais me motivam são os professores, a qualidade deles são excelentes, conteúdo abordado nas disciplinas específicas são bem diversificados, bem aplicado em cada área (Estudante 211, $4^{\circ}$ ano do curso).

Ótimos professores que se preocupam com a formação de seus alunos, no caso, formação com qualidade. Esses professores me inspiram (Estudante 348, $3^{\circ}$ ano do curso).

É importante ressaltar que o docente tem um papel importante na formação dos estudantes. Conforme mencionado por 38,7\% dos participantes, a inspiração em professores da Educação Básica foi um dos principais motivos apontados pela escolha do curso. Para Quadros (2005) bons professores exercem influência sobre a carreira que o estudante seguirá. De forma complementar, para Sá e Santos (2016, p.108) "Formadores que valorizam a carreira docente tendem a demonstrar prazer em sala de aula e estimular seus estudantes à docência”. Nesse sentido, é fundamental que o professor tenha ciência da sua importância e do seu papel social.

De modo geral, levando em consideração todos os fatores relacionados ao curso, a pesquisa solicitou que os estudantes assinalassem a motivação para a sua conclusão, em uma escala de 1 a 7 . A média dos participantes foi de 5,8, sendo as maiores médias para os 
ingressantes e concluintes. Entre os fatores de motivação, apontados com frequência, destacamse o fato de ser uma instituição pública e de qualidade, a estrutura oferecida, a boa convivência com os servidores, ter um diploma de ensino superior, a família, amigos e a oportunidade de mudar a vida de uma pessoa.

Em relação aos fatores que desmotivam os estudantes, prevaleceram questões de ordem econômica, pois muitos mencionaram que precisam trabalhar para se manter no curso, inviabilizando muitas vezes realizar os trabalhos, estudar e participar de atividades extracurriculares oferecidos pela Instituição, conforme evidenciado nos depoimentos.

A quantidade de horas necessárias para o estágio que por ser muito elevada acaba
tornando-se um empecilho para o término do curso. As horas de atividade
extracurricular também atrapalham bastante pois quem trabalha não tem como
cumpri-las (Estudante $93,2^{\circ}$ ano do curso). A grande quantidade de horas a serem cumpridas (atividades teórico-prática) - 200 horas, e para quem trabalha fica difícil cumprí-las (Estudante 190, $4^{\circ}$ ano do curso).

Alguns professores que pregam que o curso é para todos e nos jogam uma quantidade de trabalho extremamente grande e eu e muitos que trabalham não conseguem acompanhar (Estudante 233, $1^{\circ}$ ano do curso).

É importante mencionar novamente que alguns pontos elencados não podem ser alterados, conforme consta na Resolução CNE/CP 02/2015 (BRASIL, 2015). No entanto, a maneira de realizá-los pode ser negociada de acordo com a realidade local. O fato de ouvir as demandas e dar voz aos estudantes faz com que se sintam valorizados e pertencentes à Instituição, atendendo, assim, uma das necessidades psicológicas básicas que é o pertencimento, essencial para a motivação, conforme aponta Reeve (2006). Além disso, essa negociação é importante para garantir a permanência dos estudantes no curso e, assim, contribuir para diminuir a carência de professores de Química no mercado de trabalho.

Levantamentos como esse são de grande relevância para o processo de tomada de decisão nos cursos de formação de professores. É importante que cada coordenação de curso em conjunto com o corpo docente promova constantemente discussões a respeito do desenvolvimento das atividades, sempre levando em consideração a realidade local do câmpus e o atendimento às necessidades psicológicas básicas dos estudantes. Entender os fatores que motivam e desmotivam o estudante a continuar no curso é o primeiro passo para propor ações que visam à sua permanência e êxito no curso. 


\section{CONSIDERAÇÕES FINAIS}

Os resultados deste estudo evidenciaram que, em geral, os estudantes estão motivados para permanecer e concluir o curso de Licenciatura em Química no IFSP. É fato que existem fatores que acabam desmotivando o aluno em determinados momentos. Alguns, por exemplo, não podem ser alterados, como a distribuição das horas nas diversas atividades do curso. No entanto, a sua forma de realização pode ser discutida e estruturada de acordo com a realidade de cada câmpus.

Em virtude da desvalorização docente e baixa procura pelos cursos de Licenciatura, estamos vivenciando um cenário preocupante, no qual há demanda, mas não há docentes disponíveis para supri-la, especialmente em algumas áreas, como a de Química. Se não promovermos constantemente discussões a respeito das melhorias que podem ser feitas nos cursos, corremos sério risco de aumentar cada vez mais a evasão e contribuir para aumentar esse cenário desfavorável da Educação no Brasil. Dialogar com as demandas dos estudantes é fundamental, pois se sentem parte da Instituição e responsáveis pelo seu processo formativo.

Para que possamos mudar o cenário desfavorável em que estamos, é fundamental a participação e o envolvimento de todos, gestores, servidores e estudantes. É preciso repensar as nossas atuações nos cursos de formação inicial de professores, tendo em mente a motivação dos estudantes. Manter os estudantes motivados, passa pelo atendimento das necessidades psicológicas básicas de autonomia, competência e pertencimento. Nesse sentido, cabe à Instituição criar condições para que essas necessidades sejam atendidas, pois, dessa forma, se envolverão nas atividades propostas e, consequentemente, permanecerão e concluirão com êxito o curso. Espera-se que este trabalho, aliado a outros disponíveis na literatura, possa contribuir para aprofundar os conhecimentos da área, assim como suscitar debates visando a melhorias nos cursos de formação de professores de Química.

\section{REFERÊNCIAS}

ARAÚJO, Isac Rufino. A motivação de licenciandos em música sob a perspectiva da teoria da autodeterminação. 2015. Dissertação (Mestrado em Música) - Universidade Federal do Rio Grande do Norte, Natal, 2015.

BEGO, Amadeu Moura; FERRARI, Tarso Bortolucci. Por que escolhi fazer um curso de Licenciatura? Perfil e motivação dos ingressantes da Unesp. Revista Química Nova, v.41, n.4, p. 457-467, 2018. Disponível em:

http://static.sites.sbq.org.br/quimicanova.sbq.org.br/pdf/ED20170318.pdf Acesso em 16 jan. 2020. 
BRASIL. Resolução CNE/2015 n.2 de julho de 2015. Define as Diretrizes Curriculares Nacionais para a formação inicial em nível superior (cursos de licenciatura, cursos de formação pedagógica para graduados e cursos de segunda licenciatura) e para a formação continuada. Diário Oficial da União, Brasília, 25 jun. 2015.

BRASIL. Instituto Nacional de Estudos e Pesquisas Educacionais Anísio Teixeira (Inep). Censo da Educação Superior 2018: notas estatísticas. Brasília, 2019.

CANUTO, Valdiane Rodrigues. Fatores extrínsecos e intrínsecos que motivam a permanência dos alunos do curso em tecnologia em hotelaria do Instituto Federal de Educação, Ciência e Tecnologia do Ceará com base na teoria da autodeterminação. 2018. Dissertação (Mestrado) - Universidade Federal do Ceará, Fortaleza, 2018.

DAMASCENO, Deangelis; GODINHO, Mariana da Silva; SOARES, Márlon Herbert Flora Barbosa; OLIVEIRA, Anselmo Elcana de. A formação dos docentes de Química: uma perspectiva multivariada aplicada à rede pública de ensino médio de Goiás. Revista Química Nova, v.34, n.9, p.1666-1671, 2011. Disponível em http://static.sites.sbq.org.br/quimicanova.sbq.org.br/pdf/Vol34No9_1666_30-ED10999.pdf Acesso em: 15 jan. 2020.

DECI, Edward.L; RYAN, Richard.M. Intrinsic motivation and self-determination in human behavior. New York: Plenum Press, 1985.

DECI, Edward L; FLASTE, Richard. Por que fazemos o que fazemos: entendendo a automotivação. Negócio editora, 1998.

FERRARI, Tarso Bortolucci; CORTELA, Beatriz Salemme Corrêa. Perfis e motivações de estudantes de cursos de Licenciatura em Química: uma revisão bibliográfica. Revista Iluminart, n. 16, IFSP, 2018. Disponível em: http://revistailuminart.ti.srt.ifsp.edu.br/index.php/iluminart/article/view/341 Acesso em 23 mar. 2020.

GATTI, Bernardete Angelina; BARRETTO, Elba Siqueira de Sá; ANDRÉ, Marli Eliza Dalmazo Afonso de; ALMEIDA, Patrícia Cristina Albieri. Professores do Brasil: novos cenários de formação. 351 p. Brasília: UNESCO, 2019.

GIL, Antonio Carlos. Métodos e técnicas de pesquisa social. 5. ed. São Paulo: Atlas, 1999.

GUIMARÃES, Sueli Édi Rufini; BORUCHOVITCH, Evely. O Estilo Motivacional do Professor e a Motivação Intrínseca dos estudantes: Uma Perspectiva da Teoria da Autodeterminação. Psicologia: Reflexão e Crítica, Porto Alegre, v.17, n.2, p.143-150, 2004. Disponível em: http://www.scielo.br/pdf/prc/v17n2/22466.pdf Acesso em 16 fev. 2020.

GUIMARÃES, Sueli Édi Rufini ; BZUNECK, José Aloyseo. Propriedades psicométricas de um instrumento para avaliação da motivação de universitários. Ciências \& Cognição, vol. 13, p.101-113, 2008. Disponível em: http://www.cienciasecognicao.org/pdf/v13/m318210.pdf. Acesso em 15 jun. 2020.

JULIÃO, Murilo Sérgio da Silva; DA COSTA, Izabel Cristina Azevedo; BEZERRA, Ângela Cristina Sampaio. Fatores geradores de motivação e desmotivação nos licenciandos em 
Química de uma universidade pública no nordeste brasileiro. Revista Tchê Química, v.15, n.30, 2018.

LÜDKE, Menga; ANDRÉ, Marli Eliza Dalmazo Afonso de. Pesquisa em educação: abordagens qualitativas. $2^{\text {a }}$ ed.Rio de Janeiro : E.P.U, 2013.

MAZZETTO, Selma Elaine; BRAVO, Claudia Christina; CARNEIRO, Sá. Licenciatura em Química da UFC: perfil sócio-econômico, evasão e desempenho dos alunos. Revista Química Nova, v.25, n.6B, p.1204-1210, 2002. Disponível em:

http://static.sites.sbq.org.br/quimicanova.sbq.org.br/pdf/Vol25No6B_1204_23.pdf Acesso em 19 fev. 2020.

MILARÉ, Tathiane; WEINERT, Patrícia Los. Perfil e perspectivas de estudantes do curso de Licenciatura em Química da UEPG. Revista Química Nova, v.39 n.4, p. 522-529, 2016.

Disponível em: http://static.sites.sbq.org.br/quimicanova.sbq.org.br/pdf/v39n4a17.pdf Acesso em: 25 fev. 2020.

QUADROS, Ana Luiza de; CARVALHO, Emerson; COELHO, Flávia dos Santos; SALVIANO, Luciana; GOMES, Maria Fernanda P.A; MENDONÇA, Paula Cristina; BARBOSA, Rosemary Karla. Os professores que tivemos e a formação da nossa identidade: um encontro com nossa memória. Ensaio Pesquisa em Educação em Ciências, v. 7, n. 1, p. 49-64, 2005. Disponível em: http://www.scielo.br/pdf/epec/v7n1/1983-2117-epec-7-0100004.pdf Acesso em 06 mar.2020.

REEVE, Johnmarshall. Motivação \& Emoção. Rio de Janeiro: LTC, 2006.

RIBEIRO, Marcel Thiago Damasceno. A formação inicial e iniciação à docência em Química na UFMT: histórias e experiências. Revista Prática Docente. v.4, n.1, p.275-301, 2019. Disponível em: http://periodicos.cfs.ifmt.edu.br/periodicos/index.php/rpd/article/view/435 Acesso em 25 mar. 2020.

RUIZ, Antonio Ibañez.; RAMOS, Mozart Neves; HINGEL, Murílio. Escassez de professores no Ensino Médio: propostas estruturais e emergenciais. Relatório CNE/CEB. Brasília: MEC, 2007. Disponível em: http://portal.mec.gov.br/cne/arquivos/pdf/escassez1.pdf Acesso em 26 mar. 2020.

RYAN, Richard.M; DECI, Edward.L. Self-Determination theory and the facilitation of Intrinsic motivation, social development, and Well-Being. American Psychologist, v. 55, n.1, p. 68-78, 2000a.

RYAN, Richard.M; DECI, Edward.L. Intrinsic and extrinsic motivations: Classic definitions and new directions. Contemporary Educational Psychology, v. 25, n.1, p. 54-67, 2000b.

SÁ, Carmen Silvia da Silva; SANTOS, Wildson Luiz Pereira. Motivação para a carreira docente e construção de identidades: o papel dos pesquisadores em Ensino de Química. Revista Química Nova, v.39, n.1, p. 104 -111, 2016. Disponível em: http://static.sites.sbq.org.br/quimicanova.sbq.org.br/pdf/v39n1a15.pdf Acesso em 16. fev. 2020. 
SCHNETZLER, Roseli Pacheco; ARAGÃO, Rosália Maria Ribeiro. Importância, sentido e contribuições de pesquisas para o ensino de Química. Química Nova na Escola, n.1, 1995. Disponível em: http://qnesc.sbq.org.br/online/qnesc01/pesquisa.pdf Acesso em 22. mar. 2020.

TOLEDO, Evelyn Jeniffer de Lima; COUTINHO, Henrique do Nascimento. Formação de professores: licenciatura em química humanizada sob a ótica dos alunos da unb. Revista Prática Docente, v. 5, n. 1, p. 193-213, 2020. Disponível em:

http://periodicos.cfs.ifmt.edu.br/periodicos/index.php/rpd/article/view/571. Acesso em 16.jun.2020.

Recebido em: 5 de maio de 2020.

Aprovado em: 3 de julho de 2020. 